\title{
Assaying activity and assessing thermostability of hyperthermophilic enzymes
}

\author{
Roy M Daniel and Michael J Danson*
}

Department of Biological Sciences, University of Waikato, Private Bag 3105, Hamilton, New Zealand

and

*Department of Biology and Biochemistry, University of Bath, Bath, BA2 7AY, UK

Proofs to: R M Daniel, Department of Biological Sciences, University of Waikato, Private Bag 3105, Hamilton, New Zealand

Fax: +64-7-8384324

Email r.daniel@waikato.ac.nz

Running title: Assaying enzyme activity and thermostability

\section{Introduction}

There is now a wide variety of intra- and extra-cellular enzymes available from organisms growing above $75^{\circ} \mathrm{C}$, and having sufficient stability to allow assay well above this temperature. For some of these enzymes, to assay below even $95^{\circ} \mathrm{C}$ will involve measurement below the optimal growth temperature for the organism. The purpose of this chapter is to cover practical aspects of enzyme assay procedures that are specific to high temperatures. Since by far the commonest routine assessment of enzyme stability is activity loss, and because it is always unwise to measure enzyme activity without being confident of its stability during the assay, we include an outline of procedures for measuring enzyme activity loss/stability at high temperatures.

There are a number of useful reviews of the effects of temperature upon enzyme activity [1], and these apply as much to reactions at $100^{\circ} \mathrm{C}$ as at $37^{\circ} \mathrm{C}$. However, enzymes stable at $100^{\circ} \mathrm{C}$ have a number of advantages as research subjects. For example, they can be used to investigate enzymes that are particularly unstable when isolated from mesophiles, to slow reactions without the use of cryosolvents, and to probe the effect of temperature on enzyme and protein behavior over a very wide temperature range. They can also be used to study enzyme behavior under conditions that would denature most enzymes, since enzymes resistant to heat are also, at room temperature, resistant to organic solvents, 
chaotropic agents, and proteolysis. Clearly, such stable enzymes also have a variety of applications in biotechnology, where protein stability may be an important practical and economic factor.

Enzyme activity increases with temperature, usually by a factor of $1.4-2.0$ per $10^{\circ} \mathrm{C}$, depending upon the Arrhenius activation energy. As the temperature is raised, at some point the enzyme will begin to denature during the assay. The extent will depend upon the stability of the enzyme and the temperature, but also on the duration of the assay, and on factors such as the buffer composition and the degree of stabilisation of the enzyme by substrate/cofactor, etc. This combination of activity acceleration and increasing denaturation with temperature has unfortunately led to the production of activity versus temperature graphs that exhibit a so-called "temperature-optimum" peak for the enzyme. The position of this peak can of course be shifted by tens of degrees by varying the assay duration, and these graphs give little biochemical information above the temperature at which denaturation becomes significant during the assay. As a tool to aid in the development of enzyme technology processes, with the assay duration linked to the process time, these graphs may be useful in comparing enzymes. Their use should otherwise be avoided, as should the term "temperatureoptimum" derived from them.

However, there is recent evidence [2] that some enzymes may have genuine temperature optima. That is, at some point in the temperature profile, an enzyme may actually become less active as the temperature is raised, but this is not caused by denaturation. While it is not clear yet if this phenomenon is widespread among enzymes, where it is present this genuine temperature optimum will be an important and diagnostic characteristic of an individual enzyme, alongside $\mathrm{pH}$ optimum, stability, and kinetic properties.

The acceleration of enzyme rates with temperature obviously means that, in the absence of denaturation, the specific activity of an enzyme increases as the temperature is raised. However, as far as it is possible to judge, enzymes from hyperthermophiles growing optimally above $95^{\circ} \mathrm{C}$ have similar specific activities to those from organisms growing optimally at $25^{\circ} \mathrm{C}$ when assayed at their respective in vivo temperatures. Moreover, both sets of enzymes will have similar stabilities at their optimal or "evolved" growth temperature. This, and much other evidence, has led to the notion that enzyme activity and stability are connected via dynamics, molecular motions being clearly required for catalysis, while too much movement will lead to unfolding/denaturation. While this is a gross generalisation, which begs many questions (local or global dynamics, what timescales?), it explains most of the evidence so far [3]. However, it should be remembered that (relatively) small changes in activity and stability can be generated separately by in vitro directed evolution if the appropriate selection pressures are applied [4], indicating that some changes in thermostability are not necessarily linked to changes in activity and that the observed inverse correlation of the two properties may reflect in part the process by which any enzyme has adapted.

\section{Enzyme Assays above $75^{\circ} \mathrm{C}$}

\section{A) General Comments}

As for all enzyme assays, continuous assays are to be preferred to discontinuous, although at high temperature a number of factors render continuous assays more difficult. The unavailability of "linker" enzymes stable above $75^{\circ} \mathrm{C}$ will often prevent the use of coupled enzyme assays, while only electrically-heated spectrophotometer cuvette holders are practical above $80^{\circ} \mathrm{C}$, and pressurised cuvettes will be needed above $100^{\circ} \mathrm{C}$. Therefore, at high temperatures, discontinuous assays will be 
more frequently used, with the concomitant need for duplicate/triplicate assays and very careful controls. It is especially important that all controls be run at the same temperature as the assay, given the instability of many substrates, products, and cofactors at elevated temperatures. In addition, control of assay conditions, especially temperature and $\mathrm{pH}$, poses particular problems at high temperatures.

In the light of these difficulties, there will be a strong temptation to do assays at lower (or as they are sometimes called, more realistic) temperatures than the growth temperature of the source organism. Where practical this should be resisted, but in the case of reactions involving heat-labile substrates or cofactors, for example, there may be no alternative but to run routine lower temperature assays, after seeking validation/comparison of these with those run at higher temperatures (possibly for very short periods). In our structure-function studies on citrate synthase [5], for example, one of the substrates, oxaloacetate has a half-life of approximately 20 seconds at $100^{\circ} \mathrm{C}$. Therefore, routine assays of the enzyme from Pyrococcus furiosus (optimal growth temperature of $100^{\circ} \mathrm{C}$ ) are carried out at $55^{\circ} \mathrm{C}$, although, with a $\mathrm{Km}$ for oxaloacetate of $10 \mu \mathrm{M}$, brief assays at $100^{\circ} \mathrm{C}$ are possible with a starting concentration of substrate in excess of $1 \mathrm{mM}$.

Assessment of enzyme activity or stability at or above $100^{\circ} \mathrm{C}$ needs considerable care. Spills of water/reaction mixture into oil baths can result in small explosions and sprays of hot oil, and the failure of any closed vessel incubating at these high temperatures can have similar results. Oil baths should be run in fume hoods, with lids raised only for manipulation. Operators should wear lab coats which include cover of the neck area, polycarbonate face shields, long insulated gloves, and use tongs for handling vessels

Before embarking on work above $100^{\circ} \mathrm{C}$, a batch of the chosen reaction vessels should be tested, filled to the experimental level and at somewhat above the experimental temperature, to assess the likely frequency of failure. Small vessels tend to be safer than larger ones. Normal Eppendorf tubes tend to pop their lids around $100^{\circ} \mathrm{C}$, but the screw-top version with ' $\mathrm{O}$ ' rings is satisfactory up to about $120^{\circ} \mathrm{C}$, but not at $130^{\circ} \mathrm{C}$. For fast temperature equilibration and integrity at high temperatures, sealed capillary tubes are ideal. We use $2 \mathrm{~mm}$ OD, $100 \mathrm{~mm}$ long, soda-glass melting-point capillaries, containing up to 80ul of liquid. With a $>10 \mathrm{~mm}$ air space at each end these can be sealed with a narrow flame without risk to the contents. Integrity is largely dependant on the end seal: we have used them up to $190^{\circ} \mathrm{C}$, and had some failures at that temperature, but with careful sealing they can be used with some confidence up to at least $160^{\circ} \mathrm{C}$. If larger vessels are absolutely essential, we have had relatively few failures up to $135^{\circ} \mathrm{C}$ with crimped Bellco tubes using new seals, but these failures can be violent and special precautions should be taken. Note that variation between batches and manufacturers is to be expected, and all incubations above $100^{\circ} \mathrm{C}$ should be treated as hazardous.

\section{B) Temperature control}

To equilibrate a cuvette in a spectrophotometer at $37^{\circ} \mathrm{C}$ is a relatively quick procedure, although a plastic cuvette may still require over 5 minutes [6]. At higher temperatures not only is this slower temperature equilibration a more serious drawback, but the cuvettes may distort. Above $60^{\circ} \mathrm{C}$ not only is equilibration of any cuvette slow, but for liquid-jacketed cuvette holders heat losses during circulation may necessitate a significant offset between the (higher) water-bath temperature circulating the liquid and the temperature required in the water-jacketed cuvette holder. The water-bath will need to be controlled by a temperature sensor actually in the cuvette for the most reliable results. Above $80^{\circ} \mathrm{C}$ even this becomes impractical, and electrically-heated cuvette holders are required. In all cases, the only reliable estimate of the temperature of the cuvette contents is a direct measurement. Temperature gradients within cuvettes can be significant at high temperatures despite lowered viscosity, and if stirred cuvettes are not used temperature measurements at both top and bottom of the 
cuvette need to be checked under experimental conditions.

Above $80^{\circ} \mathrm{C}$, even equilibration of test-tube/vial contents in a water-bath needs substantial time. Above $110^{\circ} \mathrm{C}$, we have found that only containers that are totally immersed in the oil bath will achieve oil bath temperature, although equilibration is usually slow. In any event, above $100^{\circ} \mathrm{C}$ containers should be completely immersed to prevent distillation within the container. Above $100^{\circ} \mathrm{C}$, the only reliable way to run short assays is to seal the contents in a capillary tube, and start the reaction by immersion of the capillary. Temperature equilibration can be achieved in 2-20 seconds in the temperature range 105$140^{\circ} \mathrm{C}$. Reactions can be stopped by plunging the capillary into iced water. In all these systems, there is no acceptable substitute for direct temperature measurement using a vessel and contents identical to those used for the reaction. A small, fast-response, thermistor is essential.

\section{C) Buffers}

There are many factors to consider when choosing a buffer [7], but at high temperatures the temperature coefficient will be particularly important. Although in theory any buffer can be used at high temperatures provided the $\mathrm{pH}$ is adjusted at the temperature of use, in practice there are great advantages in using buffers with low temperature coefficients $[\mathrm{d}(\mathrm{Ka}) / \mathrm{dt}]$. This will minimise $\mathrm{pH}$ change upon cooling, which is quite likely to be necessary at some point, especially if the assay is discontinuous; it will also enable buffers to be made up at room temperature without too heavy a dependance upon $\mathrm{d}(\mathrm{pKa}) / \mathrm{dT}$ values, few of which have been derived or tested above $60^{\circ} \mathrm{C}$. There are relatively few such buffers with "apparent" or "working" $\mathrm{pKa}$ values near neutrality at $90^{\circ} \mathrm{C}$ [Loosely speaking, the apparent $\mathrm{pKa}$ of a buffer is the actual $\mathrm{pH}$ value of the buffer solution with $50 \%$ of each species present, at the temperature and ionic strength of the solution: for the values quoted here we have assumed an ionic strength arising from a $100 \mathrm{mM}$ buffer solution. See ref [7] for a fuller discussion.]. Table 1 lists buffers with an apparent pKa between $\mathrm{pH} 6$ and 8 at $90^{\circ} \mathrm{C}$ which change in $\mathrm{pKa}$ by less than $1 \mathrm{pH}$ unit when cooled from $90^{\circ} \mathrm{C}$ to $25^{\circ} \mathrm{C}$. It is clear that effective buffering around neutrality with only moderate changes of $\mathrm{pH}$ with large temperature changes can be obtained only with phosphate, which will allow cooling from $90^{\circ} \mathrm{C}$ to $20^{\circ} \mathrm{C}$ with a $\mathrm{pH}$ change of $<0.2$ units; the corresponding change with Tris buffer would be 2.0 ! Phosphate buffer will thus allow activity measurements over a temperature range of $40^{\circ} \mathrm{C}$ or so in the same buffer. For most of the buffers in the table, different buffer solutions will be needed to compare activities over any greater temperature range than $15^{\circ} \mathrm{C}$. There are few buffers available with $\mathrm{pKa} \mathrm{a}_{90}$ values between 7.3 and 8.7 [borate $\mathrm{pKa} \mathrm{a}_{90}=8.7$ ], and none which will not change in $\mathrm{pH}$ by more than $1 \mathrm{pH}$ unit when cooled from 90 to $25^{\circ} \mathrm{C}$. CHES has a convenient $\mathrm{pKa}_{90}$ of about 8.1 , but a $\mathrm{d}(\mathrm{pKa}) / \mathrm{dT}$ of -0.018 .

For further details, see reference [7], or the web site at http://www.bi.umist.ac.uk/buffers.html

While thermal stability is less likely to be an issue with inorganic buffers, imidazole is known to be unstable at high temperatures [7], and little work has been done on the high temperature stability of the commonly-used, "Good", buffers.

There are no reports to date of enzymes having markedly different $\mathrm{pH}$ optima at different temperatures, but given the high $\mathrm{d}\left(\mathrm{pK}_{\mathrm{a}}\right) / \mathrm{dt}$ of the side-chains of the ionisable amino acids, especially histidine, lysine and arginine, it will not be surprising if this is found to be the case.

\section{D) Assay component stability}

If the enzyme substrate(s) or cofactor(s) are significantly heat-labile during the assay period, results will obviously be affected. The same applies to the product if product measurement is being used as the assay. This is especially important in the case of $\mathrm{NAD}(\mathrm{P})$, where oxidation/reduction is very 
widely used to follow enzyme reaction progress, but which is quite unstable at high temperature [8]. An additional complication is the possibility that the product of thermal degradation may be inhibitory; little work has been done on this possibility, and indeed for many cases where enzyme reaction components are known to degrade at high temperature, the products of this degradation are unknown or poorly characterised. Overall, not enough is known of reactant temperature stability, and if a reactant is known to occur in vivo in a hyperthermophile this does not mean it will be stable in an in vitro enzyme assay, since the organism may overcome reactant instability by a variety of means [9]. NADH and NADPH, for example, occur in hyperthermophiles (although many dehydrogenases in these organisms are linked to non-haem iron protein), but have half lives of only about 2 minutes at neutral $\mathrm{pH}$ at $95^{\circ} \mathrm{C}$ [8], and even shorter half lives at lower $\mathrm{pH}$ values. Glutamine degrades significantly even at $80^{\circ} \mathrm{C}[10]$, but is present in hyperthermophiles.

Table 2 gives approximate stability data for a variety of metabolites and coenzymes. It can be seen that for short $\left(<10 \mathrm{~min}\right.$ ) assays at $95^{\circ} \mathrm{C}$, of the compounds listed only NAD (and including NADP, NADH, NADPH) and acetyl phosphate will be degraded at a rate which renders assay results useless, but losses of ATP and ADP may be as high as $20 \%$. The situation is further complicated by the influence of reaction conditions on metabolite/coenzyme stability. For example, ATP stability is greatly affected by $\mathrm{pH}$ and metal ions [11], and NADH stability is very $\mathrm{pH}$ sensitive [12].

There are few satisfactory solutions to reactant instability. The best solution may be to run very short assays. In some cases it may be possible to modify reaction conditions ( $\mathrm{pH}$, metal concentrations) to enhance stability, but this is likely to imply assay under sub-optimal conditions. The obvious alternative, lowering the temperature, may be preferable, providing the effects of changed $\mathrm{K}_{\mathrm{m}}, \mathrm{V}_{\max }$, etc are acceptable.

An additional complication is that many metabolites/cofactors have temperature-dependent extinction coefficients; those for NADH and for potassium ferricyanide for example, are about $10 \%$ lower at $80^{\circ} \mathrm{C}$ than at $20^{\circ} \mathrm{C}$ [12]. Fourage et al [13] point out that the effect of temperature on the absorbance and $\lambda_{\max }$ of p-nitrophenol can lead to substantial errors in $\mathrm{K}_{\text {cat }}$ values measured by continuous release of $\mathrm{p}$ nitrophenol, if the calibration curve is not determined at the same temperature as the assay

\section{Effects of temperature on kinetic parameters}

\section{A) Variation of $K_{m}$ with temperature}

A variety of enzymes are known to have different $K_{m}$ values at different temperatures (Table 3). For reasons that are not completely clear, in most cases a drop in temperature results in a drop in $\mathrm{K}_{\mathrm{m}}$, or little change. For some enzymes, the biggest changes in $\mathrm{K}_{\mathrm{m}}$ occur close to the "evolved" or growth temperature of the organism. For 3-phosphoglycerate kinase from Thermoanaerobacter, for example, the $\mathrm{K}_{\mathrm{m}}$ values for both ATP and 3-phosphoglycerate are relatively unchanged over the range $40-65^{\circ} \mathrm{C}$, but rise sharply above this temperature [2]. A similar effect was found for the 3-phosphoglycerate kinases from two mesophiles, Zymomonas mobilis and an unidentified soil bacterium, but with the increase in $\mathrm{K}_{\mathrm{m}}$ values occurring at a lower temperature. Data from the glutamate dehydrogenase from Thermococcus zilligii are consistent with this pattern [14]. These findings tend to emphasis the need to carry out enzyme assays/determination of properties at the growth temperature of the source organism if the results are to have physiological significance.

\section{B) Variation of catalytic activity with temperature}

In the absence of significant denaturation or degradation of an enzyme during the assay, the rate of an 
enzyme-catalysed reaction will increase with a rise in temperature in a manner empirically described by the Arrhenius equation:

$$
\mathrm{k}=\mathrm{Ae}^{-\left(\mathrm{E}_{\mathrm{a}} / \mathrm{RT}\right)}
$$

where $\mathrm{k}=$ first-order rate constant for the conversion of substrate to products, $\mathrm{A}=$ Arrhenius constant, $\mathrm{E}_{\mathrm{a}}=$ Arrhenius activation energy, $\mathrm{R}=$ Universal Gas Constant and $\mathrm{T}=$ temperature. Using transition state theory, a similar equation can be derived:

$$
\mathrm{k}=\underline{\mathrm{k}}_{\underline{\mathrm{B}}} \mathrm{T} \mathrm{e}^{-\left(\Delta \mathrm{G}^{\circ *} / \mathrm{RT}\right)}
$$

$\mathrm{h}$

where $\mathrm{k}_{\mathrm{B}}=$ Boltzmann's constant, $\mathrm{h}=$ Planck's constant, and $\Delta \mathrm{G}^{\mathrm{o}^{*}}=$ change in standard free energy between the ground and transition states of the substrate. From both equations, a plot of ' $\ln$ [Enzyme velocity]' versus $[1 / \mathrm{T}]$ will be linear in the absence of a temperature-induced loss of catalytic activity.

There is no evidence to date that Arrhenius activation energies are systematically different in enzymes from hyperthermophiles (i.e. in very stable enzymes) and, perhaps surprisingly, for at least some of these enzymes the Arrhenius activation energies are unchanged over very large temperature ranges. The glutamate dehydrogenase from $T$. zilligii, for example, gives a linear Arrhenius plot in buffer between $5^{\circ}$ and $90^{\circ} \mathrm{C}[14]$, and in $70 \%$ methanol between $0^{\circ} \mathrm{C}$ and $-85^{\circ} \mathrm{C}$ [15].

For a more detailed discussion see reference [1].

\section{Assessing Enzyme Stability}

An assessment of enzyme stability is an important exercise before assays can be designed and carried out.

\section{A) Denaturation and degradation}

In principal, there are two ways in which enzyme activity can be lost at high temperatures: denaturation, which in principle consists of the reversible loss of the active conformation with no loss of primary structure, and degradation, which consists of irreversible inactivation involving covalent bond disruption. These are not always easy to separate. Deamidation of the amide side chain of Asn and Gln residues, succinimide formation at Glu and Asp, and oxidation of His, Met, Cys, Trp and Tyr, are the most facile and common amino acid degradations. The rates of protein degradation by these mechanisms are greatly accelerated at high temperatures, and can thus play an important role in the thermo-inactivation of enzymes (For a brief discussion see ref [3]). Both denaturation and degradation can be assessed by measuring activity loss, but if the loss is not reversible this cannot be taken as showing that degradation is the cause, as in practice denaturation is usually not readily reversible.

Although there is clear evidence that denaturation can occur in the absence of degradation, the converse is not as obviously the case. In proteins at neutral $\mathrm{pH}$, degradation only occurs at conveniently measurable rates at high temperatures, and almost all studies of protein degradation have used proteins that were of mesophilic origin and were therefore fully denatured at the temperatures used. In those few cases where very stable proteins have been investigated, there is evidence that at least in the temperature range $85-110^{\circ} \mathrm{C}$, denaturation still precedes degradation $[16,3]$. This fits the evidence that the chemical mechanisms for irreversible degradation in proteins require a certain local molecular flexibility. For example, at $37^{\circ} \mathrm{C}$ the rate of deamidation has been shown to be higher both 
in small peptides with high flexibility and in denatured proteins than in folded proteins. A survey of environments around Asp and Asn residues in known three-dimensional protein structures suggests that the rigidity of the folded protein greatly decreases the intramolecular imide formation necessary for further degradation. In the numerous X-ray crystal structures studied, the peptide-bond nitrogen could not approach the side-chain carbonyl carbon closely enough to form the succinimide ring (See ref [3]).

A detailed assessment of protein degradation processes and rates is beyond the scope of this work. However, the commonest degradative processes are deamidation of the side chain of asparagine and glutamine residues and succinamide formation at glutamate and aspartate resides (in both cases often followed by hydrolysis of the resulting succinamide), and tests for ammonia evolution or peptide bond cleavage (such as gel electrophoresis or electrospray mass spectrometry) are probably the simplest to use if degradation is suspected.

\section{B) Assessing activity loss at high temperatures}

The commonest method used for assessing enzyme stability is the determination of activity loss with time at a given temperature. Although this provides little information on the nature of the process or the end products, it has the virtue of ease and simplicity and it gives the information on enzyme stability that is essential for assay development.

The process mostly consists of incubating an enzyme at a given temperature, removing samples at various time intervals, rapidly cooling, and assessing activity at some lower temperature at which activity loss is known not to occur. This procedure is open to criticism because of the possibility that the enzyme may be denatured at high temperature and then renatured (thus regaining activity) rapidly enough to display activity in the cooled assayed sample. While we know of no cases where such rapid renaturation of a very thermophilic enzyme has occurred, direct high-temperature measurements of activity are a necessary accompaniment of stability measurements made in this way. The activity determined is likely to be only an approximation because of denaturation losses occurring during the assay. This, together with the effects of the presence of substrate and product in the assay will prevent a good correlation between stability assessed and remaining activity [as above], but will still greatly reduce the likelihood that an apparent high-temperature stability is actually the result of reversible denaturation.

Stabilities determined in this way are dramatically dependent upon conditions. Buffer type, $\mathrm{pH}$, and ionic strength can have major effects, as well as agents such as substrate, product, cofactors, and metal ions (especially calcium). Stability comparisons made between enzymes on this basis must be regarded as approximations only, and the conditions carefully defined.

For extracellular enzymes, in vitro assessments of stability may have some physiological significance, although it is by no means clear that in nature such enzymes are free in solution rather than associated with a surface. However, the physiological significance of in vitro stabilities of intracellular enzymes is less obvious. Apart from the potential stabilising factors mentioned above, the intracellular low water activity and the presence of high concentrations of protein are both powerful stabilising agents. In addition, some, but not all, thermophiles are known to contain metabolites that strongly stabilise proteins, although it is not certain that this is their primary function. The most effective of these agents are cyclic 2,3-diphosphoglycerate and di-myo-inositol 1,1'-phosphate, found in Methanothermus fervidus and Pyrococcus woesei, respectively. In the presence of potassium, these agents increase the half-lives of some enzymes by up to 130 -fold at $90^{\circ} \mathrm{C}$ [17]. 


\section{Acknowledgements}

We thank the Royal Society of New Zealand for the award of the James Cook Fellowship to RMD, and the Biotechnological and Biological Sciences Research Council, UK for financial support to MJD. We also thank our graduate students for their contribution over the years towards solving the problems associated with high temperature enzyme assays.

Table 1. Buffers with low $\mathrm{d}(\mathrm{pKa}) / \mathrm{dt}$ values and pKa values between pH $6-8$ at $90^{\circ} \mathrm{C}$

\begin{tabular}{|l|c|c|c|c|}
\hline Buffer & pKa ${ }^{*}{ }^{*}$ & $\mathbf{d}(\mathbf{p K a}) / \mathbf{d T}$ & $\mathbf{p K a}_{\mathbf{2 5}}{ }^{*}$ & $\begin{array}{c}\Delta \mathbf{p H} \\
\mathbf{9 0} \mathbf{C ~} \rightarrow \mathbf{2 5}^{\circ} \mathbf{C}\end{array}$ \\
\hline PIPES & 6.1 & -0.0085 & 6.7 & 0.6 \\
\hline MOPS & 6.5 & -0.011 & 7.2 & 0.7 \\
\hline Phosphate(pKa 2$)$ & 6.6 & -0.0028 & 6.8 & 0.2 \\
\hline HEPES & 6.7 & -0.014 & 7.6 & 0.9 \\
\hline HEPSO & 6.9 & -0.014 & 7.8 & 0.9 \\
\hline POPSO & 7.0 & -0.013 & 7.8 & 0.8 \\
\hline HEPPS/EPPS & 7.3 & -0.011 & 8.0 & \\
\hline
\end{tabular}

Data are taken from L. Stevens, In "Enzyme Assays, a Practical Approach ” [ R. Eisenthal and M.J. Danson, eds] p.317. Oxford University Press, Oxford, UK. (1992), and R.J. Beynon and J.S. Easterby, "Buffer Solutions: The Basics", BIOS Scientific Publishers, Oxford, UK. (1996).

*The pKa values given above are apparent rather than thermodynamic values, assuming a $100 \mathrm{mM}$ buffer solution. The temperature at which the pKa applies is denoted by subscript. 
Table 2 Some metabolite and coenzyme stabilities

Metabolite/coenzyme

NAD

FAD

FMN

Acetyl phosphate

$\mathrm{CoASH}$

Acetyl-CoA

ATP

ADP

AMP
Percentage remaining after $1 \mathrm{~h} / 95^{\circ} \mathrm{C}$

$<5$

100

75

$<10$

100

100

40

50

95

Data from R.M. Daniel, In “Thermophiles” (J.Weigel and M.W.W.,Adams, eds) p.299. Taylor \& Francis, London, UK (1998). 
Table 3 Examples of $\mathrm{Km}$ variation with temperature

\begin{tabular}{|c|c|c|c|}
\hline Enzyme & Substrate & $\begin{array}{c}\mathbf{K m} \\
(\mathbf{m M})\end{array}$ & $\begin{array}{l}\text { Temp } \\
{ }^{\circ} \mathrm{C}\end{array}$ \\
\hline \multirow[t]{2}{*}{$\begin{array}{l}\text { 3-phosphoglycerate kinase } \\
\text { (Thermoanaerobactor sp) [2] }\end{array}$} & 3-phosphoglycerate & $\begin{array}{l}0.8 \\
1.1 \\
1.9\end{array}$ & $\begin{array}{l}40 \\
65 \\
76\end{array}$ \\
\hline & ATP & $\begin{array}{l}0.7 \\
0.7 \\
1.5 \\
\end{array}$ & $\begin{array}{l}40 \\
65 \\
77 \\
\end{array}$ \\
\hline \multirow[t]{3}{*}{$\begin{array}{l}\text { Glutamate dehydrogenase } \\
\text { (Thermococcus zilligii strain AN1) [13] }\end{array}$} & 2-oxoglutarate & $\begin{array}{c}0.2 \\
0.52 \\
1.7\end{array}$ & $\begin{array}{l}14 \\
60 \\
80\end{array}$ \\
\hline & $\mathrm{NH}_{4} \mathrm{Cl}$ & $\begin{array}{c}2.0 \\
5.7 \\
15.5\end{array}$ & $\begin{array}{l}14 \\
60 \\
80\end{array}$ \\
\hline & glutamate & $\begin{array}{l}1.39 \\
1.93 \\
9.12 \\
\end{array}$ & $\begin{array}{l}40 \\
60 \\
80 \\
\end{array}$ \\
\hline
\end{tabular}

Data from T.M. Thomas and R.K. Scopes, Biochem. J. 330, 1087 (1998), and R.C. Hudson, L.D. Ruttersmith and R.M. Daniel, Biochem. Biophys. Acta 1202, 244(1993).

\section{References}

[1] K.J. Laidler, Methods Enzymol.. 63, 234 (1979).

M. Dixon, E.C. Webb, C.J.R. Thorne and K.F. Tipton, “Enzymes” Longman, London, UK.(1979).

[2] T.M. Thomas and R.K. Scopes, Biochem. J. 330, 1087 (1998).

U.Gerike, N.J. Russell, M.J. Danson and D.W. Hough, Eur. J. Biochem. 248, 49 (1997).

C.L. Kydd, H. Connaris, D.W. Hough, C.D. Reeve and M.J. Danson (1999) Biochem. $J$. Submitted 
[3] R.M. Daniel, M. Dines, and H.H. Petach, Biochem. J. 317, 1 (1996).

[4] S. Akanuma, A. Yamagishi, N. Tanaka and T.Oshima, Eur. J. Biochem. 260, 499 (1999).

L. Giver, A. Gershenson, P-O. Freskgard and F.H. Arnold, Proc. Natl. Acad. Sci. USA 95, 12809 (1998).

[5] M.J. Danson and D.W. Hough, Trends in Microbiology ㅁ, 307 (1998).

[6] R.A. John, In "Enzyme Assays, a Practical Approach” [ R. Eisenthal and M.J.

Danson, eds] p.59. Oxford University Press, Oxford, UK. (1992).

[7] L. Stevens, In "Enzyme Assays, a Practical Approach ” [ R. Eisenthal and M.J.

Danson, eds] p.317. Oxford University Press, Oxford, UK. (1992).

R.J. Beynon and J.S. Easterby, "Buffer Solutions: The Basics", BIOS Scientific

Publishers, Oxford, UK. (1996).

[8] R.M. Daniel and M.J. Danson, J.Mol.Evol. 40, 559 (1995).

[9] R.M. Daniel, In “Thermophiles” (J.Weigel and M.W.W.,Adams, eds) p.299. Taylor \& Francis, London, UK (1998).

[10] H.D.Ratcliffe and J.W. Drozd, FEMS Micro. Lett.3, 65 (1978).

[11] M. Tetas and J.M. Lowenstein, Biochemistry 2, 350 (1963).

F. Ramirez, J.F. Marecek, and J. Szamosi, J. Org. Chem.45, 4748 (1980).

[12] K.A.J. Walsh, R.M. Daniel and H.W. Morgan, Biochem. J.,201, 427 (1983).

[13] L.Fourage, M. Helbert, P. Nicholet, and B. Colas, Analyt. Biochem. 270, 184 (1999).

[14] R.C. Hudson, L.D. Ruttersmith and R.M. Daniel, Biochem. Biophys. Acta 1202, 244 (1993).

[15] N. More, R.M. Daniel, H.H. Petach, Biochem. J. 305, 17 (1995).

[16] R. Hensel, L. Jacob, H.Scheer and L. Lottspeich, Biochem. Soc. Symp. 58, 127 (1992).

[17] R. Hensel and L. Jacob, Syst. Appl. Micobiol. 16, 742 (1994). 